\title{
LEITURA E LEITORES: o que dizem as crianças sobre a leitura feita na escola
}

\author{
RENATA B. SIQUEIRA FRAUENDORF
}

UNICAMP. Mestrado em Educação - FE/Unicamp. Doutoranda em Educação pela Faculdade de Educação - Unicamp - GEPEC. Brasil. ORCID: 0000-0001-5567-3235. E-mail: re.frau@, hotmail.com

\section{HELOÍSA HELENA DIAS MARTINS PROENÇA}

UNICAMP. Mestrado em Educação - FE/Unicamp. Doutoranda em Educação pela Faculdade de Educação - Unicamp - GEPEC. Brasil. ORCID: 0000-0001-7222-0529. E-mail: heloisamartinsproenca@gmail.com

\section{GUILHERME DO VAL TOLEDO PRADO}

Doutor em Linguística Aplicada. Livre-docente em Educação Escolar. Programa de PósGraduação em Educação da Faculdade de Educação da UNICAMP. Coordenador do GEPEC

- Grupo de Estudos e Pesquisas em Educação Continuada. ORCID: 0000-0002-2415-8369.

E-mail: toledo@unicam.br 


\section{LEITURA E LEITORES: o que dizem as crianças sobre a leitura feita na escola}

Este texto apresenta uma pesquisa que pretendeu conhecer as relações entre as práticas de leitura propostas por professoras e o impacto na formação dos alunos enquanto leitores. A investigação realizou-se com um grupo de crianças, na faixa etária de 4 a 10 anos, pertencentes a escolas da rede pública e privada, em diferentes municípios brasileiros. Foi desenvolvida por profissionais da educação que fazem parte do grupo de estudos colaborativo GRUPAD - Grupo de Estudos Alfabetização em Diálogo vinculado ao GEPEC Grupo de Estudos e Pesquisas em Educação Continuada - da Faculdade de Educação da Unicamp, no ano de 2016. A participação e escuta das crianças aconteceu por meio de rodas de conversas, mediadas por professoras-pesquisadoras, em que no mínimo cinco questões, previamente elaboradas, foram propostas para disparar a conversa e troca entre os alunos. Nesse processo de elaboração da pesquisa e análise das narrativas dialogamos, principalmente com autores como: Bakhtin (2003; 2010); Lebrun (2013); Lerner (2002); Passegi (2014); Petit (2013); Prado (2015). Neste artigo elegemos três perguntas-provocação para apresentar as reflexões tecidas e que já indiciam que a presença de situações de leitura realizadas pelo professor é identificada pelas crianças como parte da rotina escolar, entretanto esse movimento ainda tem sido insuficiente para formar alunos leitores e críticos. Apesar da intencionalidade e planejamento dos professores para este momento da rotina, os percursos de leitores, da maioria dos alunos participantes da pesquisa, estão sendo marcados mais por livros lidos do que experiências de leitura literária significativas.

Palavras-chave: metodologia narrativa; formação de leitores; formação continuada; leitura pelo professor.

\section{READING AND READERS: what children say about reading done at school}

This text presents a investigation that aimed to know the relationships between the reading practices proposed by the teachers and the impact on the students' training as readers carried out with a group of children, in the age group of 4 to 10 years, belonging to schools in the network. public and private, in different Brazilian municipalities. It was developed by education professionals who are part of the collaborative study group GRUPAD - Group of Studies Literacy in Dialogue linked to GEPEC - Group of Studies and Research in Continuing Education - of the Faculty of Education at Unicamp, in 2016. The children's participation and listening took place through conversation circles, mediated by teacher-researchers, in which at least five questions, previously elaborated, were proposed to trigger the conversation and exchange between students. In this process of research development and analysis of narratives, we dialogue mainly with authors such as: Bakhtin (2003; 2010); Lebrun (2013); Lerner (2002); Passegi (2014); Petit (2013); Prado (2015). In this article we have chosen three provocation questions to present the reflections made and which already indicate that the presence of reading situations carried out by the teacher is identified by the children as part of the school routine, however this movement has still been insufficient to train student readers and critics. Despite the teachers' intentionality and planning for this moment in their routine, the paths of readers, of most students participating in the research, are being marked more by books read than significant literary reading experiences.

Keywords: narrative methodology; training of readers; continuing education; reading by the teacher. 


\section{LECTURA Y LECTORES: lo que dicen los niños sobre la lectura realizada en la escuela}

Este texto presenta una investigación que tuvo como objetivo conocer la relación entre las prácticas de lectura propuestas por los maestros y el impacto en la formación de los estudiantes como lectores llevados a cabo con un grupo de niños, de 4 a 10 años, pertenecientes a escuelas de la red. públicos y privados, en diferentes municipios brasileños. Fue desarrollado por profesionales de la educación que forman parte del grupo de estudio colaborativo GRUPAD - Grupo de Estudios de Alfabetización en Diálogo vinculado a GEPEC - Grupo de Estudios e Investigación en Educación Continua - de la Facultad de Educación de la Unicamp, en 2016. La participación y escucha de los niños se llevó a cabo a través de círculos de conversación, mediados por profesores-investigadores, en los que se propusieron al menos cinco preguntas, previamente elaboradas, para activar la conversación y el intercambio entre los estudiantes. En este proceso de desarrollo de investigación y análisis de narrativas, dialogamos principalmente con autores como: Bakhtin (2003; 2010); Lebrun (2013); Lerner (2002); Passegi (2014); Petit (2013); Prado (2015). En este artículo, elegimos tres preguntas de provocación para presentar las reflexiones hechas y que ya indican que la presencia de situaciones de lectura realizadas por el maestro es identificada por los niños como parte de la rutina escolar, sin embargo, este movimiento aún ha sido insuficiente para capacitar a los lectores y críticos estudiantes. A pesar de la intencionalidad y planificación de los maestros para este momento de rutina, los caminos de los lectores, de la mayoría de los estudiantes que participan en la investigación, están marcados más por libros leídos que por experiencias significativas de lectura literaria.

Palabras clave: metodología narrativa; entrenamiento de lectores; educación continua; Lectura del profesor.

\section{plurais}

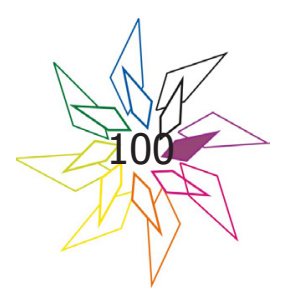




\section{LEITURA E LEITORES: o que dizem as crianças sobre a leitura feita na escola}

\section{Introdução}

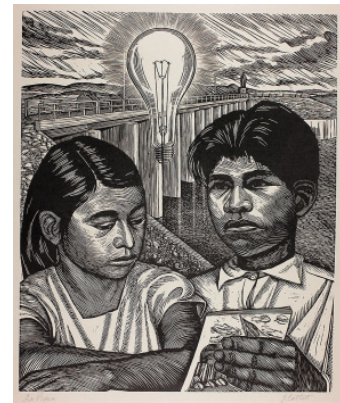

Elizabeth Catlett

O grupo de estudos colaborativo GRUPAD - Grupo de Estudos Alfabetização em Diálogo 2 - vinculado ao GEPEC - Grupo de Estudos e Pesquisas em Educação Continuada - da Faculdade de Educação da Unicamp, que nasceu em novembro de 2010 a partir da demanda de professoras recém-formadas e iniciantes na carreira docente, com a necessidade de discutir sobre a prática escolar com parceiras mais experientes, é constituído atualmente por educadoras ${ }^{3}$ no exercício da docência nos anos iniciais do ensino fundamental e na educação infantil; por profissionais da coordenação pedagógica escolar; formadoras de professores que atuam nas redes públicas e particulares de ensino, entre outras profissionais.

Nos encontros realizados quinzenalmente de forma presencial na Faculdade de Educação, ou por plataforma de vídeo conferência em tempos de distanciamento social - compartilhamos experiências, ideias e saberes, que muitas vezes transbordam esse espaço e continuam ecoando por meio de redes sociais como Facebook, Instagram ou no grupo de WhatsApp. Seja por qual

1 No lugar do uso de uma epígrafe convencional, optamos por utilizar uma outra linguagem que a não verbal. Para a escolha das imagens tomamos como critério cenas que dialogassem com a ideia de leitura subjetiva, leitor empírico e que marcam sobremaneira nossas reflexões durante o processo da pesquisa e encontros do grupo. Todas as imagens são de domínio público e foram retiradas do site: https:/www.artic.edu. Acesso em 06/06/2020. Imagem: La Presa - Elizabeth Catlett.. 2 O Grupad é coordenado pelas duas primeiras autoras e supervisionado pelo terceiro autor.

3 Optamos pelo uso no feminino uma vez que o grupo é constituído em sua maioria por profissionais do sexo feminino. 
caminho for, nosso maior desejo é procurar entender melhor o universo profissional que vivenciamos, pois, concordamos com a ideia de que ao narrarmos os processos que "nos tocam", "que nos provocam tremores", como diz LARROSA (2014), elegemos aspectos do campo profissional para potencializar nossas reflexões coletivas. Somos testemunhas do quanto esse movimento todo tem contribuído para a produção colaborativa de saberes entre escola básica e universidade.

Para compreender o contexto da pesquisa realizada consideramos importante fazer uma breve retrospectiva do percurso trilhado até o ano de 2019. Em 2014 decidimos, em parceria com as integrantes do grupo na época, nos aprofundar nos estudos da leitura como prática social (KLEIMAN, 2004; LERNER 2002) e nos propusemos a fazer uma leitura programada do livro $O$ amor de uma boa mulher (2014), de Alice Munro, edição da Companhia das Letras, objetivando construir sentidos coletivos sobre os contos lidos ora no coletivo, ora individualmente, bem como refletir sobre o processo de constituição de leitoras literárias de uma autora totalmente desconhecida para as participantes. Nos pautamos na mesma lógica para o ensino de uma leitura com compreensão sugerido por Kleiman (2002, p.10), ao afirmar que "é na interação, isto é, na prática comunicativa em pequenos grupos, com o professor ou com seus pares, que é criado o contexto para que aquela criança que não entendeu o texto o entenda". Embora a autora faça a afirmação centrada no processo de aprendizagem das crianças, acreditávamos que o adulto leitor também se aproveitaria dessa interação num contexto semelhante. Partimos do princípio de que nosso grupo é constituído por profissionais que atuam em contextos diversos, são parceiras de profissão, com maior ou menor experiência na prática docente e de leitura e por isso esse tipo de intercâmbio poderia ser proveitoso. É preciso deixar claro que no grupo a relação que se estabelece não é a de professora e aluna, nem ocorre de forma hierarquizada, mas sim uma relação entre profissionais que se revezam na condução e proposição dos encontros.

Aprendemos muito durante essa prática, principalmente com a decisão das participantes em interromperem a leitura do livro, por não se sentirem atraídas pelos contos. Movimento que nos ajudou a refletir sobre o que leva um leitor a desistir de um livro, seja pela falta de "interação" com a autora, falta de interesse pelo tema ou aproximação com o contexto.

4 Leitura programada - a leitura que serve para a ampliação da proficiência leitora, sobretudo, no que se refere à extensão dos textos trabalhados ou à seleção de textos/livros mais complexos. Nela, o professor divide o texto em trechos que serão lidos um a um, autonomamente e, depois, comentados em classe em discussão coletiva. (BRAKLING 2004. Disponível: https://www.escrevendoofuturo.org.br/EscrevendoFuturo/arquivos/912/040720121E-_Leitura_Formacao de Leitores.pdf acesso em 02/06/20

\section{plurais}


Durante os anos de 2015 e 2016, demos continuidade aos estudos da leitura como prática social, porém mudamos os encaminhamentos e partimos para a produção de narrativas escritas das nossas experiências pessoais como leitoras. Ao rememorar nossas experiências iniciais de leitura pudemos contemplá-las e relacioná-las ao vivido naquele momento. Entendemos que esse movimento retrospectivo e introspectivo (CLANDININ e CONNELLY, 2011) muito tem a nos ensinar, já que ao rememorar nossas histórias vividas como leitoras em contextos e tempos outros, também produzimos novos conhecimentos contribuindo para nos tornar pessoas e profissionais mais capacitadas para a prática docente.

A escrita de narrativas permitiu, também, a tomada de consciência daquilo que nos constitui como leitoras, pois como afirma Petit (2013, p.107) "a leitura não é uma diversão, é algo que me constrói”, o que entendemos ser extremamente potente em espaços de formação de professores e de autoformação:

\begin{abstract}
A noção da identidade literária supõe, pois, uma espécie de equivalência entre si e os textos: textos de que eu gosto, que me representam, que metaforicamente falam de mim, que me fizeram ser o que sou, que dizem aquilo que eu gostaria de dizer, que me revelaram a mim mesmo. Essa noção requer e estabelece a memória de textos que perfizeram um percurso - evoca um universo literário - mas inclui também uma relação com a língua, com a escrita e com a singularidade do modo de ler [...] (ROUXEL, 2013, p.70).
\end{abstract}

As reflexões provocadas a partir da partilha dessas narrativas continuaram reverberando entre nós e mobilizaram o desejo das participantes conversarem com estudantes para conhecer o que eles pensavam sobre a leitura feita pelo professor a fim de ampliarmos nossos conhecimentos incluindo além dos saberes dos adultos e de teóricos, que vinhamos estudando e conhecendo, o saber produzido pelas próprias crianças.

Por fim, toda essa produção das narrativas das experiências literárias das participantes do GRUPAD resultou num livro, publicado no ano de 2020, intitulado "Formação de leitores: Narrativas de profissionais da educação" pela editora Pedro e João e organizado pelos mesmos autores deste artigo. 


\section{Sobre a pesquisa}

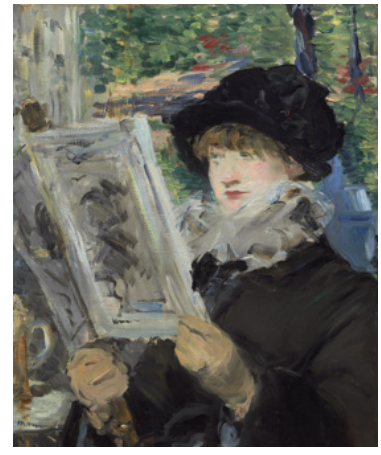

Édouard Manet ${ }^{5}$

A investigação intitulada “O que as crianças nos dizem quando se tornam leitoras?" foi realizada com um grupo de alunos, na faixa etária de 4 a 10 anos, pertencentes a escolas de redes públicas e privada de ensino, em diferentes municípios brasileiros. A escolha por essa faixa etária deu-se por dois motivos: ser o público atendido pela maioria das participantes do grupo e por nos permitir observar as diferenças e semelhanças das experiências de leitura oferecidas em diferentes etapas escolares e em diferentes regiões. A participação e escuta dos alunos aconteceu por meio de rodas de conversas, mediadas por professoras-pesquisadoras, em que no mínimo 4 perguntasprovocação ${ }^{6}$ a proposta para finalização de uma frase, previamente elaboradas, foram propostas para disparar a conversa e troca entre seus participantes.

Nesse processo de elaboração da investigação e análise das narrativas dialogamos principalmente com autores como Bakhtin (2003; 2010); Lebrun (2013); Lerner (2002); Passegi (2014); Petit (2013) e Prado (2015). Neste artigo elegemos duas perguntas- provocação e a finalização da frase para apresentar as reflexões tecidas e nos ajudar a identificar os saberes construídos a partir da pesquisa em questão.

\footnotetext{
5 Imagem: Woman Reading. Édouard Manet.

6 Identificamos as perguntas como perguntas-provocação, pois as questões formuladas e utilizadas nas rodas tinham o objetivo de serem um disparador para as conversas nas rodas e interação entre os participantes. De forma alguma pretendia-se restringir a conversa a um rol de perguntas e respostas como um questionário a ser mecanicamente respondido.
}

\section{plurais}


Em que se difere e em que se assemelha a narrativa da experiência vivida por uma criança da educação infantil de um aluno do $5^{\circ}$ ano? Em que se difere e em que se assemelha a narrativa da experiência vivida por uma criança que estuda em uma escola pública ou em uma escola particular? Essas foram algumas das inquietações que nos perseguiram ao realizar essa investigação.

Para essa pesquisa-formação - compreendendo que nessa metodologia todos os envolvidos seja investigador, participantes são sujeitos ativos do processo e portanto formam e se formam (BRAGANÇA 2009)- alguns dos membros do grupo (professoras de escola básica em sua maioria) convidaram algumas crianças (no máximo 20) para participar de uma roda de conversa sobre leitura, uma vez que consideramos a roda como uma metodologia de investigação que pode oportunizar a circulação de informações, a troca entre as crianças, além de instigá-las a dizerem o que pensam não somente sobre o que foi sugerido, como também, a dizerem outras coisas que relembram no momento em que dialogam. Segundo Passeggi et al (2014, p. 86), essa metodologia

(...) visa a olhar a infância de modo a levar em conta a alteridade da criança, legitimando-a como ser capaz de refletir ao narrar suas vivências e, por essa via, trazer informações importantes sobre as escolas da infância e sobre a criança-sujeito.

Durante nossos encontros elaboramos coletivamente um roteiro semiestruturado com quatro perguntas-provocação abertas e a proposta para finalização da seguinte frase: "Um bom leitor é ..." para orientar o diálogo da roda. As mediadoras ${ }^{7}$ iniciaram explicando às crianças o que aconteceria e a finalidade da proposta. Algumas disseram fazer parte de uma tarefa que precisavam realizar para a "escola" que frequentavam. De modo geral, todas seguiram o roteiro e foram lançando outras perguntas-provocação que brotaram da própria interação a partir dos enunciados ditos e não ditos, a fim de incentivar os participantes da roda a expressarem algo em relação às experiências de leitura vividas na escola e fora dela. As conversas foram gravadas e depois transcritas.

Entre os vários desafios enfrentados, destacamos o processo de elaboração da própria pesquisa com um grupo inexperiente (em sua maioria) nesse tipo de sistematização, seja ao definir qual seria o foco do estudo e o público; seja ao formular perguntas-provocação ou mesmo para escolher a metodologia para construção dos dados; inexperiência também para organizar os registros, fruto das conversas, na etapa posterior. Durante o processo de escrita das conversas tecidas

7 Nomearemos mediadora porque as rodas foram mediadas por professoras, coordenadoras, todas mulheres, daí a opção pela concordância no feminino. 
durante as rodas, algumas das mediadoras puderam refletir sobre a experiência vivida e constataram que nem sempre conseguiram lançar as melhores provocações para os alunos. Algumas, inclusive, se viram presas à ideia de que a pergunta em si deveria ser apenas respondida, o que na opinião delas empobreceu o momento de interação e diálogo no grupo de alunos. Contudo ouvir, escrever e refletir sobre os enunciados dos estudantes ajudou a todas a compreenderem o quanto eles podem nos comunicar sobre os processos de ensino vivenciado e como os alunos aprendem.

Participaram da pesquisa 131 crianças, entre 4 e 10 anos de idade, sendo um grupo de Educação Infantil e 11 grupos do Ensino Fundamental, distribuídas em 12 rodas de conversa nos municípios de Ariquemes (RO), Campinas (SP), São José do Rio Preto (SP), Capivari (SP) e Monte Mor (SP). Entendemos que essa diversidade foi um fator importante na constituição de nossas reflexões e análises, pois constatamos muita semelhança em relação à alguns aspectos, independente da faixa de idade ou contexto vivido pela criança.

As perguntas-provocação que elegemos para o momento da roda, intencionavam produzir um diálogo pautado nas práticas de leitura que já estávamos, de certo modo, habituadas a acompanhar ou a desenvolver em nossas experiências como educadoras. Optamos por 4 questões e uma uma frase a ser complementada que, de certo modo, apresentavam uma relação entre si. São elas: 1. Na sua sala de aula, a professora costuma ler histórias para você? Que histórias você mais gosta de escutar nesse momento? E o que menos gosta? Por quê? / 2. Na sua opinião por que você acha importante aprender a ler? / 3. O que você gosta mais no momento da leitura: quando alguém lê para você ou quando você mesmo(a) lê? Por quê? / 4. Você costuma levar livros de histórias da escola para casa? / 5. (se a resposta for afirmativa) Você lê sozinho(a) ou alguém lê para você? Quem? (se a resposta for negativa) Gostaria de levar livros? Por quê? / Para finalizar, propõe-se que cada criança da roda pense num complemento para a frase: Um bom leitor é....

Para a discussão que propomos aqui, elegemos as seguintes perguntas-provocação para tecer algumas reflexões: 1. Na sua sala de aula a professora costuma ler histórias para você? Que histórias você mais gosta de escutar nesse momento? E o que menos gosta? Por quê? / 2.Na sua opinião por que você acha importante aprender a ler? / Complete a frase: Um bom leitor é...

Fizemos esta escolha por entender que esse conjunto de disparadores está relacionado ao que pensam as crianças sobre as situações de leitura experienciadas em sala de aula e por revelar

\section{plurais}


situações para além daquilo que é programado ou estruturado pela professora como situação didática de leitura, assim como apresentar pistas de como a identidade de leitor vai se constituindo por meio da relação com a leitura literária e interação com os pares.

\section{O que nos dizem as crianças?}

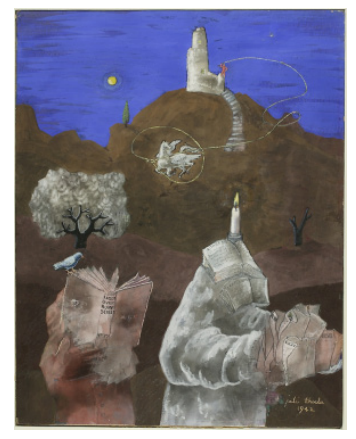

Julia Thecla ${ }^{8}$

Em nossa sociedade e nos espaços acadêmicos ainda gera certo estranhamento uma investigação que toma como principal colaborador as crianças, ainda mais quando o objetivo não é o de falar delas, mas sim de aprender com elas. Essa inversão da lógica é algo que nos encanta justamente por legitimar as crianças como produtoras de conhecimento e cultura. Ao escutarmos o que as crianças dizem e pensam, corremos risco de causar desordem ao que se está estabelecido em certas escolas e nas formas de pensar a leitura, principalmente,

Quando o propósito que a instituição apresenta é um só - aprender a ler ou, no máximo, ser avaliado [...] Quando o trabalho é feito com uns poucos livros que, além do mais, pertencem ao gênero "texto escolar", se dificulta ainda mais a possibilidade de que apareçam diferentes maneiras de ler. Por outro lado, permitir o ingresso de uma única modalidade de leitura e de um único tipo de texto facilita o exercício de uma importante exigência institucional: o controle rigoroso da aprendizagem. (LERNER, 2002, p.77)

Além disso, concebemos que nós somos sujeitos constituídos pela linguagem ao mesmo tempo em que a constituímos, e é nesse processo de interação constante, mediado pelas enunciações de diferentes sujeitos, que vamos construindo a nossa humanidade.

8 Imagem: Books - Julia Thecla.

\section{plurais}


Em outras palavras, compreender a linguagem da criança e esta como sujeito que enuncia e que, ao enunciar, habita o mundo com voz própria é fundamental para pensar que a linguagem, a língua e a fala não são entidades abstratas, mas enunciados (concretos), ditos por sujeitos que, por meio deles, se constituem, nos constituem e também constituem um modo de ser e habitar o mundo.(RÉ, PAULA e MENDONÇA, 2014,p. 19)

Portanto, entendemos que ao considerar com relevância as palavras ditas e não ditas pelas crianças, damos a ver esse processo de constituição do sujeito, sem hierarquizações.

O conjunto de enunciados da primeira pergunta-provocação "Na sua sala de aula, a professora costuma ler histórias para você? Que histórias você mais gosta de escutar nesse momento? E o que menos gosta? Por quê?"; revelou que a leitura feita em voz alta pelo professor é uma prática que parece estar incorporada às rotinas das diferentes turmas que participaram das rodas de conversa, independente da faixa etária, tipo de estabelecimento ou região em que foi realizada. De forma unânime as crianças responderam afirmativamente a essa pergunta, revelando que professores costumam ler histórias nas salas de aula. Essa situação nos indica que houve um certo avanço no trabalho de leitura, se tomarmos como referência os Parâmetros Curriculares Nacionais (PCNs) que, em 1988 indicava:

A leitura em voz alta feita pelo professor não é uma prática muito comum na escola. E, quanto mais avançam as séries, mais incomum se torna, o que não deveria acontecer, pois, muitas vezes, são os alunos maiores que mais precisam de bons modelos de leitores. (PCN de Língua Portuguesa de $5^{\mathrm{a}}$ a $8^{\mathrm{a}}$ Série, 1998; p. 19)

A primeira pergunta-provocação nasceu justamente do desejo de saber se a leitura em voz alta feita pelo professor era algo reconhecido e identificado pelos participantes da roda como uma prática comum, uma vez que compreendemos que o professor pode desempenhar um papel preponderante como modelo de leitor para seus alunos. De acordo com Lerner (2002, p. 95),

Para que a instituição escolar cumpra com sua missão de comunicar a leitura como prática social, parece imprescindível uma vez mais atenuar a linha divisória que separa as funções dos participantes na situação didática. Realmente, para comunicar às crianças os comportamentos que são típicos do leitor, é necessário que o professor os encarne na sala de aula, que proporcione a oportunidade a seus alunos de participar em atos de leitura que ele mesmo está realizando, que trave com eles uma relação "de leitor para leitor".

\section{plurais}


Ideia que também é defendida por Lebrun (2013, p.147),

Cabe ao professor [...] tornar-se um professor de leitura que dá o exemplo de um leitor apaixonado e engajado nas descobertas, nas decepções, nas hesitações e nos entusiasmos. Assim, a classe se torna um lugar de objetivação da experiência estética, que corresponde a uma sublimação da subjetividade, um lugar de negociação de sentidos, um lugar de escuta do outro, um lugar de tolerância, um lugar de manifestação crítica, um lugar de escuta de si: enfim um lugar de intersubjetividade, onde a leitura se torna um prazer de gourmet partilhado, que remete ao convívio.

Ainda como parte dessa primeira provocação foi pedido aos estudantes que dissessem o que mais gostavam e o que menos gostavam no momento da leitura, bem como justificassem a opinião emitida. Como se tratava de uma roda de conversa, é preciso esclarecer que nem todas as crianças responderam individualmente, ou verbalizaram suas ideias e que, muitas vezes, os comentários e falas entre elas eram muito parecidos, tanto por representarem aquilo que se gostaria de dizer, como também por se apoiarem na fala do colega e talvez se sentirem mais confortáveis ao reproduzi-la, o que não será alvo de análise nessa produção.

De modo geral, os alunos indicaram que apreciam a experiência de leitura realizada pelo professor em sala de aula, e ao comentarem o que mais gostavam nesse momento, uma grande maioria relacionou o gosto à temática, às personagens ou simplesmente informando o título da história. Já uma minoria de crianças conseguiu evocar sensações, sentimentos, relembrar de elementos do vivido no ato da escuta de histórias.

Ao refletirmos sobre as narrativas produzidas pelas crianças a partir desta provocação pudemos perceber que um grande grupo de leitores que, independente da faixa etária, local ou rede de ensino, revelava ter uma consciência mais inaugural de si como leitor, como que aflorando, em um estágio inicial. A forma de se relacionarem com o texto era mais espontânea, e de certo modo mais superficial no sentido de indicarem aquilo que está explícito na história como por exemplo: "o que mais gosto nesse momento é histórias de animais, ou histórias com desenhos, ou histórias assustadoras, ou ainda histórias com final feliz". Outros informavam as personagens ou títulos que mais gostavam, como: "o que mais gosto nesse momento é Os Três Porquinhos, ...Chapeuzinho Vermelho,... Patinho feio,... Bela e a Fera, entre outros. Por fim, ainda nesse grupo, alguns alunos comentaram diante dessa provocação a forma de que gostavam de ouvir histórias, informando que gostavam quando a leitura em voz alta era realizada com apoio de fantoches, ou quando o professor 
mostrava ilustrações enquanto lia. Entretanto, também tivemos um menor grupo de leitores que pareciam identificar-se com o texto no plano mais afetivo, partilhando uma experiência vivida de forma mais subjetiva ou relacionada a uma outra experiência vivida, com uma análise atrelada a sensibilidade, como podemos observar no seguinte trecho:

Roda 3 - mediadora Raquel ${ }^{9}$

Leão: Ah, eu gosto, nois se lembra do conto de fadas, da creche lá, as tias também liam pra nós, mó legal!

Espantalho: "Uma parte que eu gosto é quando ela lê e a gente fica imaginando tudo."

Roda 4 - mediadora Lygia

Zangado: “...é quando começa a ficar meio criativo, sabe...começa a ficar meio da hora, meio radical, sabe? Ai eu gosto..."

Roda 6 - mediadora Carolina

Beto: "Quando a professora começa a ler uma parte muito engraçada e começa a sorrir com a gente e começa a falar parte do texto."

Helena: "Que nem a Violeta estava falando também ...eu me sinto dentro da história, é muito legal."

Violeta: "Também, antes dela começar ela comenta o que vai ocorrer, qual o titulo."

Quando as crianças falam sobre suas preferências na relação com os textos literários, seja de forma mais superficial ou mais aprofundada, nos possibilita inferir que as relações estabelecidas com o momento da leitura, tão presente nos cotidianos escolares, contribuem para a formação de

\footnotetext{
9 Para preservar o nome das mediadoras bem como dos alunos que participaram dessa investigação propusemos às pesquisadoras que escolhessem um nome de uma escritora de livros que lhes fosse significativa bem como utilizassem nomes de personagens de histórias infantis para identificar os alunos. Os nomes escolhidos foram: Cora Coralina, Ruth Rocha, Raquel de Queiroz, Lygia Fagundes Telles, Cecilia Meirelles, Carolina de Jesus, Marina Colasanti, Elena Ferrante, Hilda Hist, Conceição Evaristo, Clarice Lispector e Eva Furnari. As personagens que identificaram os alunos que participaram das rodas são referentes a: Turma da Mônica, Sitio do Pica- Pau Amarelo; Os Incríveis, O Pequeno Príncipe, Amiga Genial, Personagens de desenhos infantis variados, Alice no País das Maravilhas, O Mágico de Oz, Os Sete Anões, Harry Potter, Crônicas de Narnia. Gostaríamos de agradecer a participação e dedicação de cada uma dessas mediadoras sem as quais não teria sido possível realizar essa investigação, nem produzir essa riqueza de reflexões.
}

\section{plurais}


um sujeito sensível, que aprende e se relaciona com as palavras e textos de forma mais intensa; sujeitos em múltiplas dimensões que pensam, vivem e sentem a partir das relações que estabelecem com o mundo e com as experiências. Como afirma Rouxel (2013, p.76) "aquilo que é sentido e vivido ecoa no coração (o corpo) e no espírito do leitor: não há leitura forte sem ser sensível”.

Há um processo de constituição do sujeito na vida que passa pela forma como vai se relacionando com o universo sócio cultural e a leitura é uma das práticas que compõe esse processo. Pelas palavras das crianças podemos perceber o quanto os processos de interação são balizadores das compreensões que desenvolvem também nos momentos de ensino e de aprendizagem da leitura, pois "a palavra está presente em todo ato de compreensão e em todo ato de interpretação" (VOLÓCHINOV, 2017, p. 101). Com relação à segunda parte da questão, respondida pelas crianças, sobre "o que não gostam no momento da leitura", novamente é possível agrupar os enunciados dos alunos por assunto/tema e repetem-se histórias que dão medo e de terror; e personagens como Saci Pererê, Mula Sem Cabeça mais relacionados as lendas brasileiras. Porém, nos chamou atenção a quantidade de comentários - em torno de $20 \%$ - que indicaram que o barulho dos colegas, as conversas paralelas durante a leitura, assim como a interrupção da leitura da história ocasionada pela entrada de outras pessoas em sala, ou para a professora chamar atenção dos alunos, como aspectos que dizem não gostar no momento da leitura:

Roda 3 - mediadora Raquel

Homem de Lata: "Quando os outros alunos ficam fazendo barulho e não dá pra gente ouvir."

\section{Roda 1 - mediadora Cora}

Narizinho: "Quando os outros ficam teimando e a professora precisa parar para chamar a atenção deles. Eu esqueço da parte em que parou e dá aquele nó!"

Essa revelação do desgosto da leitura relacionada a manutenção da disciplina durante a roda é de fato algo muito presente em algumas salas de aula, pois é comum professores interromperem as leituras para chamar atenção dos alunos. Muitas vezes gasta-se uma energia muito grande em garantir um silêncio absoluto na sala e pouco se escuta o que os alunos estão querendo dizer ao se agitarem durante o momento da leitura.

\section{plurais}


Novos questionamentos brotaram dessa reflexão em nossos encontros do grupo colaborativo: Seria a história desinteressante? Seria o ato de leitura realizado de forma burocrática, no plano intelectual apenas, sem emoção e envolvimento por parte daquele que lê? Os ouvintes podem interagir com aquilo que é lido durante a leitura ou somente ao final quando têm autorização, geralmente, para responder a um questionário ou no caso dos menores para fazer um desenho?

Esse foi mais um momento em que as falas das crianças nos deslocaram, pois muitas de nós, professoras, coordenadoras, formadoras, nos enxergamos nesse lugar em que a manutenção da disciplina ganha a dimensão maior do que a própria experiência de leitura, aspecto que entendemos merecer atenção e reflexão dos formadores, professores da graduação, quando pensamos em docentes como mediadores de leitura.

Se compreendemos que a literatura só é concretizada na leitura e que a leitura pressupõe interação entre texto e leitor, e também a flutuação de impressões singulares das crianças e jovens durante a leitura (REZENDE, 2013), talvez o que tem existido em muitas salas de aula - apesar de ser uma prática presente na rotina- são apenas textos lidos e não verdadeiras experiências de e com a leitura (BELLEMIN-NOËL (2001) apud LANGLADE (2003)).

Na sequência, trazemos a segunda pergunta-provação - , "Na sua opinião, por que você acha importante aprender a ler?" - para ampliar as discussões propostas nesse artigo. Essa pergunta-provocação também nos possibilitou constatações importantes e produziu muitos sentidos para as mediadoras das rodas de conversa, porque em suas representações sobre a importância da leitura imaginaram que a maioria dos alunos diriam, que a leitura era importante para dialogar com outros mundos possíveis, bem como acessar ideias e informações de tempos outros. Porém, descobrimos, em diálogo com as ideias que os alunos revelaram nas rodas, que aproximadamente $35 \%$ dos participantes disseram que aprender a ler se fazia necessário para conseguir emprego e ganhar dinheiro, como é possível observar nos seguintes enunciados:

Roda 2 - mediadora Ruth

Magali: “... senão saber ler nem escrever a gente não vai conseguir o emprego.”

Roda 5 - mediadora Cecília

Serpente: "A gente tem que aprende a ler, pra depois, levar corriculos pro trabalho pra poder saber é... escrever lá no papel e também saber entregar o dinheiro certinho."

\section{plurais}

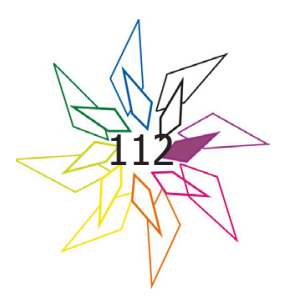


Considerando o contexto de crise sócio econômica de nosso país é totalmente compreensível que essa resposta apareça com maior frequência, o que nos permite imaginar que os alunos têm ouvido os adultos e presenciado situações em que esse problema se coloca como uma preocupação em seu cotidiano. Entretanto, esse discurso também pode ser revelador do tipo de experiências de leitura que eles participam, seja na escola ou em casa. Uma prática de leitura mais utilitarista, que para ser validada pelo sistema escolar deve estar a serviço de algo, ou ainda que funcione como pretexto, contrariando a ideia de ler por prazer; ou de uma prática de leitura mais subjetiva e sensível. Uma escolha metodológica que coloca a leitura como moeda de troca num mundo marcado por relações mercadológicas.

Enfim, os alunos podem estar construindo uma imagem de leitura muito distante ao que responde Umberto Eco quando questionado: "Para que serve esse bem imaterial que é a literatura? [...] não deve servir para nada". (2003, p.10). Numa sociedade capitalista em que tudo deve servir para algo, em que as ações são determinadas visando o lucro, a resposta de Eco sobre a literatura ainda é algo a ser perseguido por nós e pela escola. Sempre é preciso lembrar que "o texto literário é arte, não é pedagogia. Dialoga com a subjetividade, não com a técnica” (LOIS, 2010, p. 35). Nessa mesma linha, alguns alunos relacionaram a importância de ler para adquirir e compreender informação, com aproximadamente 19\% das opiniões; para aprender a escrever, com aproximadamente $11 \%$; ou relacionaram à ideia de passar nas provas, com aproximadamente $6 \%$ das respostas. Constata-se, portanto, que os dizeres das crianças, majoritariamente, vinculam a importância de ler ao contexto escolar como podemos observar no enunciado de Lila ao dizer que a leitura serve “...para a gente poder passar de ano, ir para a faculdade...” (Roda 8 - mediadora Elena).

Obviamente que adquirir e compreender informações, aprender a escrever ou sair-se bem nas provas são aspectos importantes e que merecem reflexão e discussões mais aprofundadas porque são valorizados em nossa sociedade, porém, quando os alunos (ou até mesmo os adultos) atribuem a importância da leitura a esses pontos apenas, reduzem uma prática social a situações mais empobrecidas de sentido, àquelas em que o texto se coisifica e que o valor atribuído parece ser tão somente o de acumular conhecimentos (ROUXEL, 2013). A experiência de leitura acaba por assumir um caráter de obrigação ou, simplesmente, para se agradar aos adultos, como afirma Petit (2013).

\section{plurais}


Contudo, há leitores que participaram de diferentes rodas que já parecem experimentar o texto como algo que permite pensar o mundo e construir a si mesmo. Ao contrário do grupo anterior, são alunos que demonstram estar imersos numa cultura literária ativa, uma "cultura para si" (ROUXEL, 2013). Esses alunos relacionaram a importância de ler ao fato de ser algo que permite situações como ser feliz, se distrair ou imaginar, alargar horizontes e podemos identificar alguns desses aspectos nos seguintes enunciados:

Roda 09 - mediadora Hilda:

Minerva: “...quando a gente fala com as pessoas a gente pode consegui falar de um jeito com as pessoas, tem a mente mais aberta e a gente pode conseguir oportunidades melhores na vida."

Roda 3 - mediadora Raquel:

Mágico de Oz: "Ah, porque aí a gente pode...imagina do jeito que a gente gosta, a gente pode, ai a gente já...já sabe as coisas, ai a gente pode, a gente pode...pode aprender lendo o livro."

Leituras na infância como essas podem se tornar uma verdadeira relação de amizade, "na leitura, a amizade é de repente levada à sua pureza primitiva. Com os livros, não há amabilidade. Esses amigos, se passamos a noite com eles, será porque realmente temos vontade de fazê-lo" (PROUST, p. 42). Ao ler, cada leitor constrói uma relação com a obra lida, mediada por suas sensações, emoções, vivências e aprendizados, que não podem ser medidos quantitativamente, mas ampliam os saberes desse sujeito, tanto como leitor, como pessoa que aprende e se desenvolve na cultura.

O último conjunto de enunciados que vamos analisar nesse artigo é sobre como os alunos completaram a frase "Um bom leitor é...". A finalidade desse nosso encaminhamento nas rodas de conversa era abrir uma outra possibilidade de interlocução, não mais mobilizada por perguntas, mas por uma ideia-provocação. A proposta pretendia convidar os alunos a pensarem no que caracterizava um bom leitor conforme suas representações e conhecimento de mundo. Tínhamos algumas ideias do que diriam, como por exemplo, relacionarem a qualidade de leitor ao sujeito que lê rápido, que lê muito; ou ainda, que não gagueja, que entende o texto todo. Imagens de leitor muito provavelmente formuladas a partir da própria identidade literária construída por cada uma de nós. Alguns alunos nos surpreenderam e foram muito mais longe do que poderíamos cogitar.

\section{plurais}


Para alguns dos participantes das Rodas mediadas por Elena e Clarice, a principal qualidade do leitor está relacionada ao que sabem e a postura que assumem como estudantes:

Roda 8 - Mediadora Elena:

Marisa: "ser estudioso."

Nino: "ser inteligente".

Nicola: “ ser muito inteligente imaginando o mundo da imaginação.”

Antônio: "criar."

Roda 11 - Mediadora Clarice:

Edmundo: "O tia, leitor é uma pessoa que ele sabe di tudo ... e sabi que a pessoa lê."

Já nas Rodas mediadas por Ruth e Conceição, a qualidade do leitor apareceu mais relacionada ao gênero feminino e a maioria indicou que ser um bom leitor é ser igual à mãe, à professora, à tia, à irmã. Percepção também partilhada pela antropóloga Michèle Petit, em conferência realizada em 2000, quando afirma que:

Em muitos lugares do mundo as mulheres têm desempenhado um papel preponderante como agentes do desenvolvimento cultural, junto com alguns homens que talvez tenham se integrado, tenham aceitado seu lado feminino, sem temer perder sua identidade. (PETIT 2013, p.36)

Entendemos que a questão do gênero feminino, atrelada à qualidade do leitor, é um tema que merece uma discussão mais aprofundada o que não será foco nessa produção. Porém, mais uma vez fomos deslocadas de nossas certezas e verdades diante dos enunciados dos alunos. Reflexões como: por que relacionar a qualidade de leitor a professora? Será que eles não têm outra referência de leitor fora da escola? O que significa pais e irmãos pouco serem apontados como bons leitores? Enfim, consideramos relevante a incidência de enunciados das crianças que trazem a leitura como prática feminina, preponderantemente, diante da qualificação de um bom leitor, como podemos perceber nos seguintes enunciados:

Roda 2 - Mediadora Ruth

Marina: Você! 
Ruth: Hamm... Um bom leitor sou eu? A professora?

Marina: $\dot{E}$.

Chico Bento: Você!

Ruth: Mas eu novamente!? A professora... Vai mais uma vez... Um bom leitor $e_{\text {... }}$

Chico Bento: A minha mãe!

\section{Roda 10 - Mediadora Conceição}

Alice: Meu pai, minha mãe e a professora, porque eles sabem ler muito sem errar uma palavra e um bom leitor tem que ser muito inteligente igual vocês três.

Coelho Branco: A professora porque ela lê a gente escuta e a gente vai lendo.

Rainha de Copas: É minha mãe, porque ela sempre lia para mim e eu aprendi.

Duquesa: Minha irmã que é uma boa leitora para mim, porque ela me ajuda ale.

Por fim, alguns alunos indicam perceber a leitura como uma possibilidade de transformação de si. Parecem reconhecer-se como um "leitor ativo, ora implicado, ora distanciado;(...) "um leitor singular fazendo parte integrante de uma comunidade de leitores em formação" (LEBRUN, 2013, p.138), como podemos observar nos fragmentos a seguir:

Roda 6 - Mediadora Carolina:

Helena: Aquele que aprende e sempre tem interesse.

Violeta: Aquele que sempre consegue entender a história.

Edna: Consegue meditar na história e ver o que está acontecendo.

Toninho: Consegue ser um bom ouvinte.

Roda 1- Medidora Cora:

Emília: Quem lê muito.

Narizinho: Ser bom leitor é por exemplo, ler e acalmar a outra pessoa, um bebê, uma criança.

\section{plurais}




\section{Algumas considerações finais}

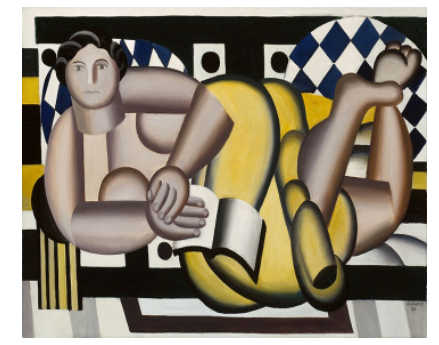

Fernand Léger ${ }^{10}$

No decorrer deste texto procuramos tecer algumas reflexões alimentadas pelas discussões e sentidos atribuídos às diferentes leituras realizadas ao longo dos encontros do Grupad, bem como aos diálogos estabelecidos com as diferentes conversas produzidas no interior de cada roda de conversa realizada junto as crianças a partir das perguntas-provocação.

Entendemos que pudemos aprender muito ao ouvir e compreender os dizeres dos alunos, assim como construir um conhecimento importante, mais robusto, sobre a importância da leitura literária dentro da escola, para a vida do sujeito e, acima de tudo, como um direito, tal como nos ensina Antônio Candido (1995).

Nossa posição enquanto um grupo de estudos colaborativo sobre a língua materna é a defesa de uma concepção de leitura como prática social, o que essa investigação e os estudos realizados até o presente momento vieram a corroborar. Compartilhamos da ideia de Ferreiro (2002, p.27) de que,

Há crianças que ingressam na língua escrita por meio da magia ( uma magia cognitivamente desafiante) e crianças que entram na língua escrita pelo treino de "habilidades básicas". Em geral, as primeiras se tornam leitoras; as outras têm um destino incerto.

Em nosso campo de atuação - formação continuada de professores/formadores - quando nos propomos a discutir com os profissionais essa temática é comum ouvir a queixa deles de que

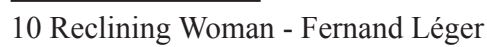

\section{plurais}


já sabem muito de leitura, e que querem algo mais importante para a vida escolar dos alunos. Sem falar que, segundo a percepção de alguns, a leitura literária ainda é considerada como algo de menor relevância, um passatempo, pretexto. Reverter essa lógica, tantas vezes colocada em prática pelos docentes e formadores, é preciso!

Após essa costura entre dizeres, percepções reflexões, chegamos a uma primeira constatação: a de que avançamos sim, quando pensamos na presença de situações de leitura como parte da rotina dos alunos, pois eles reconhecem essa ação realizada cotidianamente em sala. Também parece que temos feito algo no sentido de despertar o gosto dos alunos pelas histórias lidas por eles ou pelos professores, bem como temos conseguido abrir brechas, mesmo que diminutas, para a presença de uma dimensão mais subjetiva da leitura, principalmente na educação infantil e primeiras séries dos anos iniciais de ensino fundamental.

Por outro lado, foi possível refletir e observar a partir dos enunciados dos alunos aqui compartilhados, que isso tem sido insuficiente quando desejamos formar leitores críticos, competentes. Leitores que possam discutir com os textos, replicá-los e colocar-se em relação com outros textos e discursos (ROJO, 2004). Leitores implicados que se apropriam dos textos, leitores subjetivos que se constituem de boas experiências de leitura desde a infância, alimentando uma cultura literária e, consequentemente, forjando uma identidade literária tão profunda capaz de transformar a si mesmo.

Em comum acordo com Petit, avaliamos que "a leitura pode ser, em qualquer idade, um atalho privilegiado para elaborar ou manter um espaço próprio, um espaço íntimo, privado". (PETIT 2013, p.41). Ao escutar o que dizem a maioria dos leitores que participaram das rodas, independentemente da idade, local em que moram, tipo de escola que frequentam, constatamos que, apesar das boas intenções e de boas práticas de muitas das professoras, os percursos de leitura estão sendo mais marcados por livros lidos do que por experiências de leitura literária efetivamente. Esse grupo de leitor revela que ainda prevalece a cultura da cobrança, da avaliação, e do aprender a ler em seu sentido mais limitado.

Se nos contextos de formação continuada o discurso da relevância da importância da leitura e o jargão do despertar o gosto pela leitura já se mostram tão apropriados por profissionais da educação infantil e do ensino fundamental, perguntamo-nos, então, por que na prática estamos tão distantes disso?

\section{plurais}


A possibilidade de escutar os dizeres dos alunos nos ensinou e muito. Foi importante compreender que, esse leitor que se aproxima mais do conhecimento empírico, que tece impressões alargadas ao que ouve ou lê, estuda nas mesmas escolas, tem os mesmos professores, participou da mesma roda de outros alunos, que estão mais distantes dessa relação estética e ética com a leitura.

Ainda consideramos importante ressaltar que os sujeitos se formam nas interações que estabelecem na vida e na cultura e essas relações são mediadas pela linguagem, pela palavra. "Todos os diversos campos da atividade humana estão ligados ao uso da linguagem” (BAKHTIN, 2003, p. 261), e todos nós enunciamos de forma única e irrepetível enunciados concretos que dizem sobre quem somos e como nos relacionamos no mundo e na cultura. Assim, é de fundamental importância uma investigação em educação que efetivamente compreenda que as crianças podem contribuir com suas ideias, percepções, aprendizagens e compreensões de como essas relações ocorrem.

Finalizamos esse artigo com novos questionamentos: o que será que acontece no percurso de formação de leitor literário desse grupo menor de alunos que já faz com que se aproximem mais da perspectiva de leitores subjetivos? Eles podem nos ensinar a ver o leitor como instância da literatura? E por fim, de que literatura se alimenta esse leitor?

\section{REFERÊNCIAS}

BAKHTIN, M. Estética da Criação Verbal. São Paulo: Martins Fontes, 2003.

BRAGANÇA, I. F.S. Pesquisa-formação e histórias de vida de professoras brasileiras e portuguesas: reflexões sobre tessituras teórico-metodológicas. Revista @mbienteeducação, São Paulo, v. 2, n. 2, p. 37-48, ago./dez. 2009

BRASIL. Parâmetros Curriculares Nacionais de $5^{\mathrm{a}}$ a $8^{\mathrm{a}}$ séries do Ensino Fundamental - Língua Portuguesa. Brasília, DF: MEC/SEF,1988.

CLANDININ, J.; CONELLY, M. Pesquisa Narrativa e Histórias na pesquisa qualitativa. Uberlândia: Edufu, 2011. Traduzido do original pelo Grupo de Pesquisa Narrativa e Educação de Professores ILEEL/UFU.

ECO, U. Sobre a literatura. Rio de Janeiro: Record, 2003.

FERREIRO, E. Passado e Presente dos verbos ler e escrever. Trad. Claudia Berliner. Sáo Paulo: Cortez, 2002

\section{plurais}


KLEIMAN, A. Oficina de leitura Teoria e Prática 15a edição. Campinas: Pontes, 2013[1992]. Disponível em: https://docs.google.com/viewer?a=v\&pid=sites\&srcid=ZGVmYXVsdGRvb WFpbnxtZXN0cmFkb3Byb2ZsZXRyYXN1ZnJwZXxneDo2YzQzMWU0YjUyZTg3NWI4. Acesso em junho de 2017.

2004.

Abordagens da Leitura. SCRIPTA, Belo Horizonte, v.7, n.14, p.13-22, 1º sem.

LARROSA, J. Tremores: escritos sobre experiência. Trad. Cristina Antunes , João Wanderley Geraldi. Belo Horizonte: Autêntica Editora, 2014.

LEBRUN, M. A emergência e o choque das subjetividades de leitores do maternal ao ensino médio graças ao espaço interpretativo aberto pelos comitês de leitura. In: Leitura subjetiva e ensino de literatura. Trad. Amaury C. Moraes et al; coord. e rev. Neide L. Rezende; Rita Jover Faleiros. São Paulo: Alameda Editora,2013, pp.134-148.

LERNER, D. Ler e Escrever na Escola: o real, o possível e o necessário. Trad. Ernani Rosa. Porto Alegre: Artmed, 2002.

LOIS, Lena. Teoria e Prática da Formação do Leitor: leitura e literatura na sala de aula. Porto Alegre: Artmed, 2010.

PASSEGI, M.C et al. Narrativas de crianças sobre as escolas da infância: cenários e desafios da pesquisa (auto)biográfica. Revista Educação. Santa Maria, v. 39, n. 1 | p. 85-104, jan./abr., 2014.

PETIT, M. Leituras: do espaço íntimo ao espaço público. Trad.Celina Olga de Souza. São Paulo: Ed.34, 2013.

PRADO, G.V.T.; CUNHA, R.B. (Org.). Percursos de Autoria: Exercícios de Pesquisa. Campinas: Alínea, 2007.

PROUST, M. Sobre a leitura. Campinas: Pontes, 2003. Disponível em: https://edisciplinas.usp. br/pluginfile.php/67139/mod_resource/content/1/Proust $\% 20-\% 20$ Sobre $\% 20 a \% 201$ leitura.pdf. Acesso em junho de 2017.

RÉ, A. D.; PAULA, L.; MENDONÇA, M. C. (orgs) A Linguagem da Criança: um olhar bakhtiniano. São Paulo: Contexto, 2014.

\section{plurais}


ROJO, R. H. R. (2004) Letramento e capacidades de leitura para a cidadania. Texto de divulgação cientifica elaborado para o Programa Ensino Médio em Rede, Rede do Saber/SEE-SP e para o Programa Ler e Escrever - Desafio de Todos, CENPEC/SME- SP. SP: SEE-SP e SME-SP. Disponível: http://www.academia.edu/1387699/Letramento_e_capacidades_de_leitura_para_a_ cidadania.Acesso em junho 2017.

ROUXEL, A; LANGLADE, G; REZENDE, N (Orgs.) Leitura subjetiva e ensino de literatura. Trad. Amaury C. Moraes et al; coord. e rev. Neide L. Rezende; Rita Jover Faleiros. São Paulo: Almeida, 2013.

VOLÓCHINOV, V. Marxismo e Filosofia da Linguagem: problemas fundamentais do método sociológico na ciência ada linguagem. São Paulo: Editora 34, 2017.

Recebido em: 20 de julho de 2020 .

Inserido em: 15 de outubro de 2020.

Esta obra está licenciada com uma Licença Creative Commons Atribuição 4.0 Internacional. 